\title{
Projeções, conexões e instrumentos do princípio cooperativo da educação, formação e informação no ordemanento português
}

\author{
(Projections, connections and instruments of the \\ cooperative principle of education, training and information \\ in the Portuguese legal system)
}

Deolinda Meira ${ }^{1}$

Instituto Politécnico do Porto/ ISCAP / CEOS.PP (Portugal)

Sumário: 1. Introdução e delimitação do objeto de estudo. 2. A polivalência, as projeções e as conexões do princípio da educação, formação e informação. 2.1. Vetores, finalidades e destinatários do princípio. 2.2. O direito/dever do cooperador de participar nas atividades de educação e formação. 2.3. A relevância da educação e formação para uma efetiva participação na atividade económica da cooperativa. 2.4. A relevância da educação e formação para uma efetiva participação democrática. 2.5. A relevância da educação e formação para a profissionalização da gestão e efetiva fiscalização da cooperativa. 2.6. A relevância da informação cooperativa no relacionamento com a comunidade. 3. A reserva para a educação e formação cooperativas enquanto instrumento de concretização do princípio da educação, formação e informação. 3.1. Preliminar. 3.2. A constituição e as fontes da reserva para a educação e formação cooperativas. 3.3. Titularidade da gestão da reserva. 3.4. A natureza jurídica da reserva. 3.5. A irrepartibilidade da reserva para a educação e formação. 4. Conclusões. 5. Bibliografia.

Summary: 1. Introduction and delimitation of the object of study. 2. Polyvalence, projections and connections of the principle of education, training and information. 2.1. Vectors, purposes and beneficiaries of the principle. 2.2. The right/duty of the cooperator to participate in education and training activities. 2.3. The relevance of education and training for an effective participation in the economic

1 Professora de Direito Mercantil do Instituto Politécnico do Porto/ ISCAP / CEOS. PP. Correio eletrónico: meira@iscap.ipp.pt. Correio postal: Instituto Superior de Contabilidade e Administração do Porto, Rua de Jaime Lopes de Amorim, 4465-004 S. Mamede de Infesta, PORTUGAL. 
activity of the cooperative.2.4. The relevance of education and training for effective democratic participation. 2.5. The relevance of education and training for the professionalization of management and effective supervision of the cooperative. 2.6. The relevance of cooperative information in the relationship with the community. 3 . The reserve for cooperative education and training as a instrument to implement the principle of education, training and information. 3.1. Preliminary. 3.2. The establishment and sources of the reserve for cooperative education and training. 3.3. The ownership of the management of the reserve. 3.4. The legal nature of the reserve. 3.5. The indivisibility of the reserve for education and training. 4. Conclusions. 5. Bibliography

Resumo: O princípio da educação, formação e informação é um princípio estratégico nas cooperativas, apresentando-se como uma condição de aplicabilidade e eficácia de outros princípios, nomeadamente o princípio da gestão democrática pelos membros, o princípio da adesão voluntária e livre e o princípio do interesse pela comunidade. Trata-se de um princípio polivalente, abrangendo os vetores da educação, formação e informação, tendo como destinatários os membros, os representantes eleitos, os dirigentes, os trabalhadores da cooperativa e a comunidade. A educação e formação dirigidas à qualificação cívica, organizacional e profissional dos cooperadores, dos titulares dos órgãos de administração e fiscalização, e dos trabalhadores contribuirão para a meIhor compreensão dos modelos de governação e fiscalização da cooperativa, potenciando a profissionalização da gestão e induzindo os cooperadores a participar ativamente na sua cooperativa, a deliberar corretamente nas assembleias, a eleger conscientemente os seus órgãos e a controlar a sua atuação. A informação cooperativa, ao direcionar-se ao público em geral, permite uma inserção dinâmica das cooperativas na comunidade, sensibilizando-a quanto à natureza e benefícios da cooperação, potenciando, deste modo, adesões conscientes. Em Portugal, este princípio projeta-se no estatuto jurídico dos cooperadores, mediante o reconhecimento de um direito de participar nas atividades de educação e formação cooperativas, com a consequente obrigação de as cooperativas organizarem tais atividades de educação, formação e informação, devendo para o efeito constituir obrigatoriamente uma reserva, a qual se apresenta com caráter absolutamente irrepartível, constituindo uma das maiores especificidades do regime jurídico das cooperativas portuguesas.

Palavras-Chave: princípio da educação, formação e informação, participação, profissionalização da gestão, reserva de educação e formação cooperativas.

Abstract: The principle of education, training and information is a strategic principle in cooperatives. It is a condition for the applicability and effectiveness of other principles, namely the principle of democratic member control, voluntary and open membership, and the principle of interest for the community. It is a polyvalent principle, comprising the vectors of education, train- 
ing and information, addressed to members, elected representatives, leaders, workers of the cooperative and the community. Education and training oriented to the civic, organizational and professional qualification of the cooperators, of the management and supervisory board holders, and the workers will contribute to a better understanding of the models of governance and supervision of the cooperative, strengthening the professionalization of the management and inducing the cooperators to participate actively in their cooperative, to deliberate correctly in the assemblies, to consciously elect its bodies and to control its performance. By addressing the general public, cooperative information allows the dynamic insertion of cooperatives in the community, making them aware of the nature and benefits of cooperation, thus enhancing conscious membership. In Portugal, this principle is projected in the legal status of cooperators, through the recognition of a right to participate in cooperative education and training activities, with the consequent obligation of cooperatives to organize such education, training and information activities, and for this purpose must constitute a reserve, which is absolutely indivisible, constituting one of the significant specificities of the legal regime of Portuguese cooperatives.

Keywords: principle of education, training and information, participation, professionalization of management, reserve for cooperative education and training. 


\section{Introdução e delimitação do objeto de estudo}

Nas palavras de António Sérgio (1974, p. 235)., doutrinador e principal referência cooperativa em Portugal, no séc. $X X$, «O cooperativismo é um movimento de ascensão moral, de reforma social, que se serve, como instrumento, das necessidades económicas dos homens». A reforma moral reporta-se, segundo o autor, à importante missão pedagógica e social que o cooperativismo pode desempenhar (Costa, 1983 , p. 24). É no contexto desta missão que deve ser percebido o princípio cooperativo da educação, formação e informação, o qual se apresenta como um elemento estruturante da identidade cooperativa, sendo a melhor evidência das singularidades das cooperativas (Namorado, 2001; Fici, 2013).

Segundo Namorado (1999, p. 27), estamos perante um princípio «verdadeiramente estratégico, da maior importância como fator de legitimação social da cooperatividade e como elemento de divulgação das experiências cooperativas». Carlos Torres Lara (1983, p. 89) chama-lhe a "regra de ouro do cooperativismo», sendo condição de aplicabilidade dos outros princípios e fator da sua vigência e eficácia (Namorado, 1995).

Os princípios cooperativos integram, conjuntamente com os valores cooperativos, o conceito de Identidade Cooperativa, conceito definido pela Aliança Cooperativa Internacional $(\mathrm{ACI})$, em Manchester, em 1995. Os princípios cooperativos estão descritos no art. $3 .^{\circ}$ do Código Cooperativo português (CCoop) ${ }^{2}$, a saber: adesão voluntária e livre; gestão democrática pelos membros; participação económica dos membros; autonomia e independência; educação, formação e informação; intercooperação; e interesse pela comunidade. Os valores cooperativos, que enformam aqueles princípios, são: i) os valores de autoajuda, responsabilidade individual, democracia, igualdade, equidade e solidariedade, nos quais assenta a atividade das cooperativas como organizações; ii) os valores da honestidade, transparência, responsabilidade social e altruísmo que se dirigem ao comportamento individual dos cooperadores enquanto tais (Meira \& Ramos, 2015; Namorado, 2018).

Em Portugal, os princípios cooperativos são de obediência obrigatória, sendo inclusivamente acolhidos pela própria Constituição da República (CRP). Neste sentido, o art. $61 .^{\circ}$, n. ${ }^{\circ} 2$, da CRP dispõe que

2 Lei n. 119/2015, de 31 de agosto, com as alterações constantes da Lei n. ${ }^{\circ} 66 / 2017$, de 9 de agosto. 
«a todos é reconhecido o direito à livre constituição de cooperativas, desde que observados os princípios cooperativos». Por sua vez, a al. a) do n. ${ }^{\circ} 4$ do art. $82 .^{\circ}$ da CRP consagra que o subsetor cooperativo «abrange os meios de produção possuídos e geridos por cooperativas, em obediência aos princípios cooperativos» (Meira \& Ramos, 2015).

Nesta linha, o Código Cooperativo associa a definição legal de cooperativa à necessária obediência aos princípios cooperativos. Assim, nos termos do n. 1 do art. 2. ${ }^{\circ}$ do CCoop, serão cooperativas as "pessoas coletivas autónomas, de livre constituição, de capital e composição variáveis, que, através da cooperação e entreajuda dos seus membros, com obediência aos princípios cooperativos, visam, sem fins lucrativos, a satisfação das necessidades e aspirações económicas, sociais ou culturais daqueles».

Daí que, no seu funcionamento, o desrespeito da cooperativa pelos princípios cooperativos constituía causa de dissolução da mesma (al. h) do n. ${ }^{\circ}$ do art. $112 .{ }^{\circ}$ do CCoop). Trata-se de uma causa de dissolução compulsiva por via judicial (Meira, 2016a; Cunha, 2018).

Como veremos ao longo deste estudo, o princípio da educação, formação e informação carateriza-se por uma forte polivalência, por uma multiplicidade de destinatários, por uma intensa conexão com os demais princípios, servindo-se de um importante instrumento para a concretização das suas finalidades, que é a reserva de educação, formação e informação.

O objetivo deste estudo é o de identificar e analisar as principais projeções jurídicas deste princípio no ordenamento português, as conexões que estabelece com os demais princípios cooperativos, bem como as especificidades do regime jurídico da reserva de educação formação e informação.

\section{A polivalência, as projeções e as conexões do princípio da educação, formação e informação}

\subsection{Vetores, finalidades e destinatários do princípio}

O princípio da educação, formação e informação aparece descrito no art. 3. ${ }^{\circ}$ do CCoop, tal como foi formulado pela ACl, em 1995, a saber: "As cooperativas promoverão a educação e a formação dos seus membros, dos representantes eleitos, dos dirigentes e dos trabalhadores, de modo que possam contribuir eficazmente para o desenvolvimento das suas cooperativas. Elas devem informar o grande público, 
particularmente os jovens e os líderes de opinião, sobre a natureza e as vantagens da cooperação».

Este princípio realça a importância vital de três vetores: a educação, a formação e a informação. Os dois primeiros vetores têm uma relevância predominante no âmbito interno e o terceiro vetor no âmbito externo (Gutiérrez Fernández, 1995).

Seguindo o pensamento de lan MacPherson (1996, p. 33), «educação significará, mais do que distribuir informação, empenhar as mentes dos membros, líderes eleitos, gestores e trabalhadores na compreensão total da complexidade e riqueza do pensamento e ação cooperativa». A «formação significará assegurar que todos os que estão envolvidos nas cooperativas terão as capacidades necessárias para assumir as suas responsabilidades de modo efetivo».

A informação centrar-se-á na difusão das especificidades e vantagens da cooperação junto da comunidade em que a cooperativa se insere (García Pedraza, García Ruiz \& Figueras Matos, 2018).

O movimento cooperativo sempre assentou no paradigma do desenvolvimento integral dos seus membros. Assim, para além da componente cívica, a educação e a formação cooperativas pretendem que o cooperador adquira capacidades e conhecimentos que reforcem a sua cultura organizacional, assente nos princípios e valores cooperativos, bem como adequadas ferramentas e competências técnico-profissionais (Corberá Martínez, 2005).

Os destinatários da educação e formação cooperativas serão: os membros, os representantes eleitos, os dirigentes e os trabalhadores da cooperativa. O destinatário da informação cooperativa é a comunidade em que se insere.

Nos termos do enunciado do princípio, a educação e formação têm como objetivo o de "contribuir eficazmente para o desenvolvimento das suas cooperativas».

A dimensão externa do princípio evidencia-se no dever de informação que incide "sobre a natureza e as vantagens da cooperação», tendo como destinatários "o grande público», o mesmo é dizer a comunidade, e dentro desta nomeadamente os jovens e os líderes de opinião. A informação permitirá uma inserção dinâmica das cooperativas na comunidade, fomentando o sentido de solidariedade e de responsabilidade da população em geral, sensibilizando-a quanto à natureza e benefícios da cooperação, potenciando, deste modo, a legitimação social das cooperativas (Namorado, 1995; Macías Ruano, 2015). 


\subsection{O direito/dever do cooperador de participar nas atividades de educação e formação}

Uma das projeções internas deste princípio é o reconhecimento aos cooperadores do direito de participar nas atividades de educação e formação cooperativas (al. f) do n. ${ }^{\circ}$ 1) do art. $21 .^{\circ}$ do CCoop). O reconhecimento deste direito ao cooperador tem como contrapartida a obrigação das cooperativas de organizar tais atividades de educação e formação, devendo para o efeito constituir uma reserva "para a educação e formação cultural e técnica dos cooperadores, dos trabalhadores da cooperativa e da comunidade» (art. 97..$^{\circ}$ n..$^{\circ} 1$ do CCoop), de que falaremos mais adiante. A organização destas atividades de educação e formação é uma das competências típicas das federações e confederações de cooperativas. De facto, o art. 108, n. ${ }^{\circ} 1$, al. d) do CCoop dispõe que compete às federações e confederações «fomentar e promover a formação e educação cooperativas podendo gerir as reservas de educação e formação dos membros» (Fici, 2018a).

Faz parte do ADN das cooperativas a promoção e o fomento da educação quanto aos valores e princípios cooperativos, para que os cooperadores vivam de forma plena a sua qualidade de membro, conscientes dos seus direitos e deveres, bem como da necessária participação na atividade da cooperativa. Deve o cooperador ou o aspirante a cooperador ter plena consciência de que: (i) a cooperativa cumpre não apenas uma função económica, traduzida na satisfação das necessidades dos seus membros, mas também uma função social, evidenciada pela primazia do indivíduo e dos objetivos sociais sobre o capital, pelo reinvestimento de fundos excedentários nos objetivos de desenvolvimento a longo prazo, pela conjugação dos interesses dos membros com o interesse geral; (ii) a cooperativa é uma empresa de propriedade coletiva e gerida democraticamente pelos membros; (Meira, 2012).

O reconhecimento e a interiorização destas especificidades das cooperativas são imprescindíveis para uma adequada participação dos cooperadores na atividade da cooperativa, quer na sua dimensão económica, quer na sua dimensão política, quer na sua dimensão de gestão e fiscalização (Meira, 2017; Rodríguez González, 2018).

\subsection{A relevância da educação e formação para uma efetiva participação na atividade económica da cooperativa}

Diversamente de uma sociedade comercial, o fim principal da cooperativa não é a obtenção de lucros para depois os repartir, mas maxi- 
mizar a vantagem que os membros retiram das operações que realizam com a cooperativa ou através da cooperativa. Efetivamente, as cooperativas não têm um fim próprio ou autónomo face aos seus membros, sendo um instrumento de satisfação das necessidades individuais (de todos e de cada um) dos cooperadores, que, no seio dela, e através dela trabalham, consomem, vendem e prestam serviços (Fajardo et al., 2017). Por força do seu escopo mutualístico, as cooperativas operam com os seus membros, no âmbito de uma atividade que a eles se dirige e na qual participam cooperando (al. c) do n. 2 do art. $22 .^{\circ}$ do (Coop). Esta participação, assente na cooperação e entreajuda, traduzir-se-á num intercâmbio recíproco de prestações entre a cooperativa e os cooperadores, prestações essas que são próprias do objeto social da cooperativa (Meira, 2018a).

Deste modo, a motivação central de um cooperador não se confunde com a motivação central de um sócio de uma sociedade comercial. Para um cooperador essa motivação não será a rentabilização de um capital para o qual contribui, como acontece com os sócios das sociedades comerciais, mas a participação na atividade da cooperativa, com vista à satisfação das suas necessidades. Rui Namorado (2005, p. 162) destaca que "um sócio de uma sociedade comercial cumpre para com ela os seus deveres mais relevantes, nos termos do art. 20. ${ }^{\circ}$ do Código das Sociedades Comerciais, se realizar as entradas a que se comprometeu e se quinhoar nas perdas, se elas correrem. Pode até participar nas assembleias gerais, mas abster-se-á de qualquer outra atividade que o relacione com a sociedade enquanto sócio, sem que por isso deixe de dar conteúdo útil à sua posição. Receberá os dividendos proporcionais ao seu investimento, como qualquer outro, dando assim sentido prático à sua qualidade de sócio». Diversamente, um cooperador que se limite à subscrição dos títulos de capital, abstendo-se de qualquer participação na atividade da cooperativa, não viverá de forma plena a sua qualidade de cooperador, retirando dela poucas vantagens, mesmo se nos focarmos apenas nas económicas. Assim, por exemplo, se, no respetivo exercício, forem gerados excedentes e se os mesmos forem distribuídos, nada Ihe caberá, uma vez que, a distribuição dos excedentes cooperativos, quando tem lugar, depende do volume de transações entre cada cooperador e a cooperativa, e não do número de títulos de capital detidos por cada cooperador (Meira, 2009).

Torna-se, por isso, imperioso educar e formar o cooperador quer para utilizar os serviços da cooperativa ou para desenvolver o trabaIho que a integração na cooperativa implicará, quer para aceitar a cultura organizacional assente na observância dos valores e princípios cooperativos (Rodríguez González, 2018). 
Esta educação e formação deverão ser contínuas, mas assumem uma particular relevância no tempo inicial da aquisição da qualidade de cooperador. É neste contexto que deve ser percebida a consagração em certos ordenamentos jurídicos de um período de prova, que consiste numa medida de precaução ou prudência que visa possibilitar ao cooperador admitido certificar-se que as condições humanas, logísticas, ambientais proporcionadas são as esperadas, dando-lhe a conhecer, por via da educação e formação cooperativas, os princípios e valores cooperativos, os seus direitos e deveres e o modo peculiar de funcionamento da cooperativa. Assim, o legislador cooperativo espanhol acolheu a possibilidade de os estatutos da cooperativa de primeiro grau preverem um período de prueba, período durante o qual se dá a conhecer, ao aspirante a cooperador, o tipo de cooperativa que escoIheu, os órgãos da mesma, o seu funcionamento, os seus direitos e deveres como cooperador. Se, durante esse período, o aspirante a cooperador - que beneficia, como qualquer membro de pleno direito, de todos os serviços que lhe poderá prestar a cooperativa - demonstrar aos restantes cooperadores que foi capaz de se adaptar a esse funcionamento, será definitivamente admitido (assim, por exemplo, a Lei 5/1998, de Cooperativas de Galicia prevê, no seu art. 27. ', os socios a prueba). A este propósito, Adoración Mozas Moral (2001, p. 156) considera que a aceitação da cultura e valores cooperativos pelo aspirante a cooperador deverá ser considerado como um requisito imprescindível para aceder a qualquer cooperativa, uma vez que o seu bom funcionamento e, por consequência, o seu êxito disso depende. Esta figura foi também acolhida no direito italiano. Assim, o art. 2 527, parágrafo 2. ${ }^{\circ}$, do Codice Civile remete para o ato constitutivo a possibilidade de admissão de soci in prova. Segundo Grabiele Racugno (2006, p. 68-69), estaremos perante uma espécie de tirocínio, com a duração máxima de cinco anos, em que se permite às partes - à cooperativa, por um lado, e ao aspirante a cooperador, por outro - avaliar e ponderar a recíproca conveniência e interesse na permanência na cooperativa. A legislação cooperativa portuguesa é omissa quanto a este período de prova, no qual a educação e a formação cooperativas terão evidentemente um papel determinante na manutenção do vínculo cooperativo.

\subsection{A relevância da educação e formação para uma efetiva participação democrática}

O direito e o dever à educação e formação surgem, igualmente, como uma condição da aplicabilidade do direito de participação demo- 
crática, que decorre do princípio cooperativo da gestão democrática pelos membros (art. 3. ${ }^{\circ}$ do CCoop).

Segundo Namorado (2018, p. 31) este princípio valoriza especialmente a participação dos cooperadores no funcionamento das cooperativas e sublinha a responsabilidade dos dirigentes perante os cooperadores que os elegem.

Deste princípio resulta que os membros controlam democraticamente a cooperativa, devendo participar ativamente na formulação de políticas e na tomada de decisões fundamentais, com base na regra de um membro, um voto (art. 40. ${ }^{\circ},{ }^{\circ} 1$ do CCoop) (Meira \& Ramos, 2018; Vargas, 1999).

O direito de tomar parte na assembleia geral e de votar as propostas constantes da ordem de trabalhos constitui «o «núcleo duro» do direito de participação de um cooperador numa cooperativa, uma vez que a "assembleia geral é o órgão supremo da cooperativa» (art. 33. ${ }^{\circ}$, n. 1 do CCoop) (Fici, 2018a) .

Esta supremacia da assembleia geral significa que este órgão se encontra numa relação hierárquica relativamente aos órgãos de administração e fiscalização. Assim: (i) as mais importantes e decisivas matérias da vida da cooperativa integram-se na esfera de competências da assembleia geral, competências estas que abrangem inclusivamente matérias de gestão (arts. $38 .^{\circ}, 109 .^{\circ}$ e $110 .^{\circ}$ do CCoop); (ii) os titulares dos órgãos sociais são eleitos e destituídos pela assembleia geral (arts. $29 .^{\circ}$ e $38 .^{\circ}$, al. a) do CCoop); (iii) as deliberações da assembleia geral são obrigatórias para os restantes órgãos e para todos os membros (art. 33. ${ }^{\circ}$, n. $^{\circ} 1$ do CCoop) (Snaith, 2017; Abreu, 2018).

Esta participação na assembleia geral não se esgota no direito de emitir uma declaração de vontade através do voto. Na verdade, o direito de participar na assembleia geral abrange, para além do direito de voto, outros direitos como sejam os de estar presente (ou representado) na reunião dos cooperadores, de apresentar propostas, de intervir na discussão das propostas (Meira \& Ramos, 2019).

A educação e a formação cooperativas deverão proporcionar aos membros da cooperativa conhecimentos adequados acerca dos princípios e métodos cooperativos, de forma a que estes participem ativamente e de forma plena na sua cooperativa, deliberem corretamente nas assembleias, elejam conscientemente os seus órgãos e controlem a sua atuação.

A educação e a formação cooperativas revelam-se, deste modo, essenciais para que esta participação democrática decorra em toda a sua extensão e profundidade. 
2.5. A relevância da educação e formação para a profissionalização da gestão e efetiva fiscalização da cooperativa

Os cooperadores, quando optam por constituir uma cooperativa, pretendem satisfazer as suas necessidades através de uma empresa que eles próprios possam gerir e controlar (Fici, 2015).

Assim, o art. 29. ${ }^{\circ}$, n. ${ }^{\circ} 1$, do CCoop determina que os «titulares dos órgãos sociais são eleitos em assembleia geral de entre os cooperadores». Consequentemente, seja qual for o modelo de administração e fiscalização adotado pela cooperativa (art. 28. ${ }^{\circ}$ do CCoop), os órgãos são providos com cooperadores. Acresce que constitui um dever de cada cooperador exercer os cargos sociais para os quais tenham sido eleitos, salvo motivo justificado de escusa (art. $22 .^{\circ},{ }^{\circ}{ }^{\circ} 2$, al. b), do CCoop)(Fici, 2018b).

De acordo com os modelos de administração e de fiscalização da cooperativa previstos no art. $28 .^{\circ}$ do CCoop, a administração da cooperativa está a cargo, consoante o modelo em causa, do conselho de administração ou do conselho de administração executivo (Martins, 2018). Ora, seja qual for o modelo de administração, o órgão administrador é composto por cooperadores (art. 29. ${ }^{\circ}$ 1, do CCoop)(Costa, 2018).

A fiscalização da gestão da cooperativa e o poder de controlo sobre as decisões empresariais do órgão de administração é um aspeto crucial do governo destas entidades. A fiscalização da cooperativa está a cargo, consoante o modelo em causa, do conselho fiscal, da comissão de auditoria e revisor oficial de contas, de conselho geral e de supervisão e de revisor oficial de contas. A fiscalização da gestão da cooperativa e o poder de controlo sobre as decisões empresariais do órgão de administração é um aspeto crucial do governo destas entidades. Ora, seja qual for o modelo de fiscalização, o órgão fiscalizador é, em regra, composto por cooperadores (art. 29. ${ }^{\circ}$, 1, do CCoop).

Segundo Hans-H. Münkner (1982, p. 73), esta exigência de que os titulares dos órgãos sejam cooperadores permitirá que os interesses dos cooperadores estejam diretamente representados nos seus órgãos, apresentando a vantagem de os dirigentes da cooperativa, orientados pela sua própria experiência, terem permanentemente presentes os interesses dos cooperadores, não se desviando da finalidade principal da cooperativa, que é, como vimos, a de satisfazer as necessidades dos seus membros.

Para além de restringir a qualidade de titular dos órgãos à pessoa dos cooperadores, o Código Cooperativo não estabelece expressamente requisitos particulares de carácter técnico, de idoneidade e 
de experiência para os cargos, o que poderá representar um obstáculo acrescido à profissionalização da gestão das cooperativas, dado que todos os titulares do órgão de administração e fiscalização são cooperadores, não sendo possível recrutar, fora do universo dos membros, profissionais devidamente habilitados para exercer as funções de administrador(Münkner, 1995).

O princípio cooperativo da educação, formação e informação é a melhor evidência que o legislador cooperativo não é indiferente à necessidade de qualificação dos titulares dos órgãos responsáveis pela administração e fiscalização da cooperativa. De facto, este princípio realça a obrigação de as cooperativas, na sua atividade, assegurarem a educação e formação dos titulares dos seus órgãos eleitos, dos seus administradores e dos seus trabalhadores, ensinando os dirigentes a orientar e expandir adequadamente as atividades comuns, fornecendo-lhe conhecimentos técnicos e doutrinais necessários para o seu correto desempenho Quanto aos membros, a educação e a formação cooperativas deverão induzi-los a eleger conscientemente os seus órgãos e a controlar a sua atuação (Monzón,1995; Agirre, 2001; Mozas et al., 2005).

\subsection{A relevância da informação cooperativa no relacionamento com a comunidade}

Segundo García-Gutiérrez Fernández (1982, p. 73), a informação cooperativa relaciona-se com a função publicitária e promotora do princípio cooperativo da educação, formação e informação.

A informação cooperativa direciona-se ao público em geral, de modo a sensibilizá-lo quanto à forma empresarial especial que a cooperativa é, quanto à filosofia e ideais que prossegue, quanto à natureza e benefícios da cooperação.

Tal significa que o princípio da educação, formação e informação surge como uma condição de aplicabilidade e fator de eficácia do princípio cooperativo da adesão voluntária e livre, que corresponde ao tradicional princípio da porta aberta e que aparece formulado também no art. 3. ${ }^{\circ}$ do CCoop, nos seguintes termos: "As cooperativas são organizações voluntárias, abertas a todas as pessoas aptas a utilizar os seus serviços e dispostas a assumir a responsabilidade de membro, sem discriminações de sexo, sociais, políticas, raciais ou religiosas». Este princípio poderá ser encarado através de duas perspetivas, a saber: em primeiro lugar, a adesão deverá ser voluntária, uma vez que dependerá, exclusivamente, da vontade do cooperador; em segundo lugar, a ade- 
são deverá ser aberta a todas as pessoas, desde que estas, como candidatas a cooperadores, preencham duas condições: a possibilidade de fruírem da utilidade própria da cooperativa; e a aceitação das responsabilidades inerentes à filiação. A cooperativa satisfará, antes de mais, os interesses dos seus membros ao trabalho, ao crédito, à casa e, contemporaneamente, transbordará para o exterior, difundindo os seus serviços também a favor daqueles que, apesar de não serem membros da cooperativa, têm as mesmas necessidades que estes últimos, podendo, deste modo, gerar-se novas adesões (Meira, 2019).

O princípio da educação, formação e informação apresenta, também, uma forte conexão com o princípio cooperativo princípio do interesse pela comunidade, que aparece enunciado no art. $3 .^{\circ}$ do CCoop: "as cooperativas trabalham para o desenvolvimento sustentável das suas comunidades, através de políticas aprovadas pelos membros». Deste princípio decorre, portanto, o envolvimento das cooperativas no contexto social, cabendo aos cooperadores a escolha das políticas através das quais esse envolvimento se concretizará (Martínez Charterina, 2015; Fici, 2015).

\section{A reserva para a educação e formação cooperativas enquanto instrumento de concretização do princípio da educação, formação e informação}

\subsection{Preliminar}

A reserva para a educação e formação cooperativas é regulada pelo art. 97. ${ }^{\circ}$ do CCoop, e é de constituição obrigatória por força da lei.

Segundo o art. 97..$^{\circ}$ do CCoop, estaremos perante uma reserva obrigatória «para a educação cooperativa e a formação cultural e técnica dos cooperadores, dos trabalhadores da cooperativa e da comunidade», surgindo, deste modo como o instrumento de concretização do princípio cooperativo da educação, formação e informação.

\subsection{A constituição e as fontes da reserva para a educação e formação cooperativas}

Nos termos do art. $97 .^{\circ}$, n. ${ }^{\circ} 2$, do CCoop, reverterão para esta reserva: a parte das joias que não for afetada à reserva legal; pelo menos $1 \%$ dos excedentes líquidos anuais, provenientes das operações com os cooperadores (sendo que esta percentagem poderá ser mais elevada 
se os estatutos ou a assembleia geral assim o entenderem); os donativos e os subsídios que forem especialmente destinados à finalidade da reserva; e os resultados anuais líquidos provenientes de operações com terceiros que não forem afetados a outras reservas.

As fontes da reserva de edução e formação cooperativas refletem a variedade e a complexidade dos resultados e das fontes de financiamento que são identificáveis na estrutura financeira da cooperativa (Macias Ruano, 2015).

Refira-se quanto às joias que, nos termos do Código Cooperativo português, os estatutos da cooperativa podem exigir a realização de uma joia de admissão, pagável de uma só vez ou em prestações periódicas (art. 90. ${ }^{\circ}$, n. ${ }^{\circ}$ 1). Trata-se de uma contribuição a fundo perdido, sem que o cooperador receba qualquer direito em contrapartida. Além disso, na estrutura financeira da cooperativa, a joia ingressa no património da cooperativa e não no capital social, pelo que o cooperador não terá direito a recuperá-la em caso de demissão. Assim, o n. ${ }^{\circ} 2$ do art. $90 .^{\circ}$ do CCoop dispôs que o montante das joias "reverte para reservas obrigatórias, conforme constar dos estatutos, dentro dos limites da lei». Um mínimo de 5\% do valor das joias reverterá para a reserva legal até que esta «atinja um montante igual ao máximo do capital atingido pela cooperativa» (art. 96. ${ }^{\circ}$, n.os 2 e 3, do CCoop). O valor remanescente das joias deverá reverter para a reserva para a educação e formação cooperativas (art. 97. ${ }^{\circ},{ }^{\circ} .^{2}$, al. a) do CCoop).

A exigência da joia, no momento da admissão do cooperador, funcionará como: (i) um contributo a fundo perdido, reclamado a cada cooperador e motivado pelas despesas que o seu ingresso implica, as quais serão suportadas pela cooperativa (despesas de instalação de novos instrumentos de trabalho, despesas de manutenção acrescidas, e outras); (ii) uma forma de compensar, em parte, a contribuição dos anteriores cooperadores para o património comum da cooperativa (Fajardo, 1997, Bonfante, 1999).

Quanto aos excedentes, que correspondem aos resultados positivos provenientes da atividade económica desenvolvida entre a cooperativa e os seus membros cooperadores, o legislador determina que uma percentagem do excedente de exercício, resultante das operações com os cooperadores, reverterá para a reserva legal $\left(n .^{\circ} 2\right.$ do art. $96 .^{\circ}$ do CCoop) e para a reserva para educação e formação cooperativas (al. b) do $n .{ }^{\circ} 2$ do art. 97. ${ }^{\circ}$ do (Coop), assim como para o eventual pagamento de juros pelos títulos de capital (n. 1 do art. $100 .^{\circ}$ do CCoop).

No que respeita a esta fonte da reserva, o legislador fixou uma percentagem que «não poderá ser inferior a 1\% dos excedentes líquidos anuais», ficando, portanto, a lei satisfeita se for utilizada aquela per- 
centagem. Todavia, esta percentagem foi referida como «não inferior», compreendendo-se, então, que os estatutos da cooperativa ou a Assembleia geral possam estipular uma percentagem superior a essa.

Também poderão reverter para esta reserva os resultados provenientes de operações com terceiros que não forem afetados a outras reservas irrepartíveis. Refira-se, a este propósito, que o n. ${ }^{\circ} 2$ do art. $2 .{ }^{\circ}$ do CCoop consagra a possibilidade de as cooperativas, na prossecução dos seus objetivos, poderem «realizar operações com terceiros, sem prejuízo de eventuais limites fixados pelas leis próprias de cada ramo». Ainda que a lei não defina o que se deve entender por «terceiros», parece ser doutrina assente que, na esteira dos ensinamentos de Rui Namorado (2005, p. 184), «terceiros, de um ponto de vista cooperativo, são todos aqueles que mantenham com uma cooperativa relações que se enquadrem na prossecução do seu objeto principal, como se fossem seus membros embora de facto não o sejam». Tal significa que as atividades com terceiros, de que fala o legislador, se reportarão a atividades do mesmo tipo da atividade desenvolvida com os cooperadores, pelo que as operações com terceiros estão ainda compreendidas no objeto social da cooperativa (Meira, 2009). Ora, para preservar o escopo mutualístico -acautelando uma transformação camuflada de uma cooperativa em uma sociedade comercial ${ }^{3}$ - o legislador cooperativo impede que os resultados provenientes de operações com terceiros sejam repartidos entre os cooperadores, quer durante a vida da cooperativa, quer no momento da sua dissolução (n. ${ }^{\circ} 1$ do art. $100{ }^{\circ}$ e art. $114 .^{\circ}$ do (Coop), sendo transferidos integralmente para reservas irrepartíveis. O fundamento deste regime prende-se com o facto de os resultados gerados nas operações da cooperativa com terceiros serem lucros (objetivos); ainda que, por não serem distribuíveis pelos cooperadores, não se possa falar de escopo lucrativo, uma vez não há lucro subjetivo (Fajardo, 2015, Abreu, 2015).

Quanto à outra fonte da reserva, correspondente aos donativos e aos subsídios que forem especialmente destinados à finalidade da reserva, não podemos deixar de destacar os provenientes de entidades públicas, na decorrência do princípio da proteção do setor cooperativo e social (al. f) do art. 80. ${ }^{\circ}$ da CRP). Este princípio fundamenta, quer as discriminações positivas deste setor relativamente aos restantes, quer a previsão de medidas materiais que permitam o seu desenvolvi-

3 O Código Cooperativo proíbe a transformação da cooperativa em sociedade comercial, dispondo, no seu art. $111 .^{\circ}$, que "é nula a transformação de uma cooperativa em qualquer tipo de sociedade comercial, sendo também feridos de nulidade os atos que contrariem ou iludam esta proibição legal». 
mento. Na decorrência deste princípio, o art. $85 .^{\circ}$ da CRP dispõe, no seu n. ${ }^{\circ} 1$, o estímulo e o apoio à criação, e à atividade das cooperativas por parte do Estado, garantindo, no seu n. ${ }^{\circ}$ 2, que «a lei definirá os benefícios fiscais e financeiros das cooperativas, bem como condições mais favoráveis à obtenção de crédito e auxílio técnico». O "estímulo» decorrerá, sobretudo, de medidas de natureza legislativa que suscitem o interesse pelo exercício da atividade cooperativa, enquanto que o «apoio» decorrerá, essencialmente, de medidas de natureza administrativa que visem, em concreto, facilitar esse mesmo exercício. Esta discriminação positiva das cooperativas relativamente ao setor privado implicará, em concreto, a definição de formas de fomento à criação e atividade das cooperativas, impondo-se ao legislador a definição de benefícios fiscais e financeiros, bem como o estabelecimento de condições privilegiadas em matéria de acesso ao crédito e ao auxílio técnico (Meira, 2011a).

Refira-se finalmente que o legislador não estabelece nem um montante mínimo nem um limite máximo para a constituição desta reserva, a partir do qual as reversões para a constituição da reserva deixam de ser obrigatórias. Assim, durante toda a vida da cooperativa, subsistirá a obrigação legal de dotação da reserva de educação e formação cooperativa, independentemente da sua quantia ou do tempo decorrido (Meira, 2017).

\subsection{Titularidade da gestão da reserva}

Competirá à assembleia geral, quer a definição das linhas básicas de aplicação desta reserva, quer o controlo posterior da sua aplicação, recaindo sobre o órgão de administração da cooperativa o dever de integrar anualmente, no plano de atividades, um plano de formação para aplicação desta reserva (n. 4 do art. 97. ${ }^{\circ}$ do CCoop).

A assembleia geral pode permitir ao órgão de administração a entrega, total ou parcial, do montante desta reserva a uma cooperativa de grau superior, sob condição de esta prosseguir a finalidade da reserva em causa e de ter um plano de atividades em que aquela cooperativa seja envolvida. Não esqueçamos que entre as competências das federações e confederações se inclui a de fomentar e promover a formação e a educação cooperativas, podendo, para o efeito, gerir as reservas de educação e formação dos membros (n. ${ }^{\circ} 5$ do art. $97 .{ }^{\circ}$ e al. f) do art. $108 .^{\circ}$ do CCoop).

O Código Cooperativo permite, ainda, a possibilidade de uma parte ou da totalidade desta reserva ser afetada a projetos de educa- 
ção e formação que, conjunta ou separadamente, impliquem a cooperativa em causa e: (i) uma ou mais pessoas coletivas de direito público; (ii) uma ou mais pessoas coletivas de direito privado, sem fins lucrativos; (iii) outra ou outras cooperativas ( $n .{ }^{\circ} 6$ do art. 97. ${ }^{\circ}$ do CCoop) (Romero Civera, 2010; Meira, 2017).

\subsection{A natureza jurídica da reserva}

Numa perspetiva técnico-jurídica, a reserva é uma conta que aparece inscrita no lado do balanço onde está registado o passivo, integrando os capitais próprios da cooperativa. Assim, serão valores que, pelo facto de aparecerem inscritos no passivo do balanço, estarão representados pelos bens inscritos no ativo. Todavia, esta correspondência é global e abstrata, ou seja, não há nenhuma parte concreta do ativo que fique afetada a uma determinada reserva, salvo lei em contrário. Tal significa que as reservas não são conjuntos de bens que se destacam do património global, apresentando-se como um património autónomo, afetado a uma determinada finalidade. As reservas são «contas, em sentido contabilístico, de capitais próprios» (Pita, 1989, p. 39), sem que o legislador consagre qualquer diferenciação, para este efeito, entre as reservas, tendo em conta as finalidades das mesmas (Meira, Bandeira \& Ávida, 2018).

Daqui resulta que, diversamente de outros ordenamentos, na legislação cooperativa portuguesa, a reserva para a educação e formação cooperativas não foi configurada como um fundo especial, constituído em património autónomo, mas apenas como uma conta, em sentido contabilístico, de capitais próprios (Fajardo \& Meira, 2017).

Contudo, consideramos que os bens afetados a esta reserva, por fidelidade à sua vocação legal, só responderão pelo pagamento das dívidas contraídas na atividade a que está adstrita e não pelas restantes dívidas da cooperativa. Para esta última finalidade, existe no património da cooperativa a reserva legal, a qual se destina, em exclusivo, à cobertura de eventuais perdas de exercício ( $n .^{\circ} 1$ do art. 96..$^{\circ}$ do CCoop) (Meira, 2011b). Note-se que quando o legislador afirma que a reserva legal só poderá ser utilizada para cobrir a parte do prejuízo do exercício que não possa ser coberto pela utilização de outras reservas, ou a parte dos prejuízos transitados do exercício anterior que não possa ser coberta pelo resultado do exercício nem pela utilização de outras reservas (als. a) e b) do n. ${ }^{\circ} 4$ do art. 96. ${ }^{\circ}$ ), não está a incluir na expressão «outras reservas» a reserva de educação e formação cooperativas (Meira, 2016b). 
O nosso entendimento alicerça-se no facto de que esta reserva visa a prossecução de finalidades ligadas ao movimento cooperativo, designadamente a promoção do ensino dos princípios e técnicas cooperativas que, quando em confronto com os interesses dos credores da cooperativa, se lhes sobrepõem. Estará aqui em causa o próprio interesse público que se evidencia no estímulo e apoio à atividade das cooperativas (art. 85..$^{\circ}$ n. ${ }^{\circ} 1$, da CRP).

Assim, em coerência com as finalidades desta reserva, o legislador, na reforma de 2015, passou a consagrar, expressamente, que esta reserva não responde pelas dívidas da cooperativa perante terceiros, mas apenas pelas obrigações contraídas no âmbito da atividade a que está adstrita (n. 7 do art. 97. ${ }^{\circ}$ do CCoop) (Meira \& Ramos, 2014).

\subsection{A irrepartibilidade da reserva para a educação e formação}

A reserva para a educação e formação cooperativas, bem como a reserva legal e as reservas constituídas com resultados provenientes de operações com terceiros, serão insuscetíveis de qualquer tipo de repartição entre os membros da cooperativa (art. 99. ${ }^{\circ}$ do CCoop).

No momento da liquidação do património da cooperativa, o art. $114 .^{\circ}$ dispôs, no seu n. ${ }^{\circ}$, que, "quando à cooperativa em liquidação não suceder nenhuma entidade cooperativa nova, a aplicação do saldo de reservas obrigatórias reverte para outra cooperativa, preferencialmente do mesmo município, a determinar pela federação ou confederação representativa da atividade principal da cooperativa».

Esta impossibilidade de distribuir o património residual, em caso de liquidação, deriva, desde logo, da função social que a cooperativa é chamada a cumprir e que implica que o seu destino, após a liquidação, seja a promoção do cooperativismo (o chamado Princípio da distribuição desinteressada) (Llobregat Hurtado, 1990; Fajardo \& Meira, 2017).

Acresce que a eventual distribuição das reservas entre os cooperadores seria incompatível com o Princípio da adesão voluntária e livre. De facto, este princípio só se poderia praticar nos casos em que todos os membros da cooperativa renunciassem a uma parte dos excedentes líquidos do ativo. De contrário, os cooperadores que permanecessem na cooperativa até ao momento da liquidação seriam os únicos a beneficiar das reservas obrigatórias geradas com o esforço dos cooperadores que, entretanto, saíram da cooperativa. Mesmo no pressuposto de que nenhum cooperador se tenha demitido da cooperativa até ao momento da liquidação, qualquer distribuição destas reservas obrigatórias pelos cooperadores, na ausência de uma contabilidade analítica 
que evidenciasse o contributo de cada um deles para a formação destas reservas, causaria prejuízos aos cooperadores fundadores relativamente àqueles que ingressaram em momento posterior na cooperativa. Daí que, da mesma maneira que os cooperadores não disporão, no momento em que se demitirem da cooperativa, do direito de reclamar uma quota-parte das reservas obrigatórias, haverá da mesma forma que impedir, chegada a fase da dissolução da cooperativa, a repartição entre aqueles do ativo líquido desta última. Neste contexto, o regime da irrepartibilidade permitirá evitar demissões especulativas.

Um outro argumento contra a possibilidade de repartição assenta na particular natureza destas reservas e, sobretudo, no facto de que estas são integradas, igualmente, por resultados provenientes de operações com terceiros, que se fossem distribuídos entre os cooperadores constituiriam um dividendo, pondo em causa o escopo não lucrativo da cooperativa (Fajardo \& Meira, 2017).

\section{Conclusões}

O princípio da educação, formação e informação é um princípio estratégico e um fator de legitimação social das cooperativas, evidenciando que a cooperativa é não só uma organização económica, mas também uma organização com finalidades pedagógicas e sociais.

Estamos perante um princípio polivalente, que abrange três vetores: a educação e a formação que se projetam predominantemente no âmbito interno; e a informação que se projeta predominantemente no âmbito externo.

Este princípio tem como destinatários os membros, os representantes eleitos, os dirigentes, os trabalhadores da cooperativa e a comunidade.

Através da educação e formação visa-se contribuir eficazmente para o desenvolvimento da cooperativa, facultando aos membros, representantes eleitos, dirigentes e trabalhadores da cooperativa, capacidades e conhecimentos que reforcem a sua cultura organizacional, assente nos princípios e valores cooperativos, bem como adequadas ferramentas e competências técnico-profissionais.

A educação e formação dirigidas à qualificação cívica, organizacional e profissional dos cooperadores, dos membros titulares dos órgãos de administração e fiscalização, e dos trabalhadores contribuirão para a melhor compreensão dos modelos de governação e fiscalização da cooperativa, potenciando a profissionalização da gestão e induzindo os cooperadores a participar ativamente na sua cooperativa, a delibe- 
rar corretamente nas assembleias, a eleger conscientemente os seus órgãos e a controlar a sua atuação. Potencia-se o escopo mutualístico da cooperativa e o seu funcionamento democrático e participativo.

A informação cooperativa ao direcionar-se ao público em geral — de modo a sensibilizá-lo quanto às especificidades do modelo cooperativo, quanto à filosofia e ideais que prossegue — fomentará novas adesões e, sobretudo, adesões conscientes, permitindo uma inserção dinâmica das cooperativas na comunidade, sensibilizando a população em geral quanto à natureza e benefícios da cooperação, potenciando, deste modo, a legitimação social das cooperativas.

Este princípio tem, deste modo, uma utilidade social direta, que se reporta aos membros, titulares dos órgãos e trabalhadores da cooperativa, e uma utilidade social indireta, que se projeta em toda a comunidade.

Este princípio apresenta-se como uma condição de aplicabilidade de outros princípios, nomeadamente o princípio da gestão democrática pelos membros, o princípio da adesão voluntária e livre e o princípio do interesse pela comunidade.

Este princípio projeta-se no estatuto dos cooperadores reconhecendo-lhes um direito de participar nas atividades de educação e formação cooperativas (al. f) do n. ${ }^{\circ}$ 1) do art. $21 .^{\circ}$ do (Coop), com a consequente obrigação das cooperativas de organizar tais atividades de educação e formação, devendo para o efeito constituir uma reserva «para a educação e formação cultural e técnica dos cooperadores, dos trabaIhadores da cooperativa e da comunidade» (art. 97. ${ }^{\circ}, \mathrm{n} .{ }^{\circ} 1$ do CCoop).

A organização das atividades de educação e formação é uma das competências típicas das federações e confederações de cooperativas, podendo, para o efeito, gerir as reservas de educação e formação dos membros.

A reserva de educação formação e informação constitui uma das maiores especificidades do regime jurídico das cooperativas. Trata-se de uma reserva de constituição obrigatória por força da lei, com caráter absolutamente irrepartível e que responde apenas pelas obrigações contraídas no âmbito da atividade a que está adstrita.

\section{Bibliografia}

ABREU, Jorge Manuel Coutinho. 2015. «Empresas sociais (nótulas de identificação)». Cooperativismo e Economia Social, 37: 369-376.

ABREU, Jorge Coutinho. 2018. "Artigo 33. ${ }^{\circ}$ ». In Código Cooperativo Anotado, editado por Deolinda Meira e Maria Elisabete Ramos, 197-200. Coimbra: Almedina. 
AGIRRE, Amaia. 2001. "Los principios cooperativos «atractores» de la gestión eficiente: su medición. Aplicación al caso de Mondragón Corporación Cooperativa». CIRIEC-España, Revista de Economía Pública, Social y Cooperativa, 39: 93-113.

BONFANTE, Guido. 1999. «Delle Imprese Cooperative: art. 2511-2545». In Commentario del cod. civ. Scialoja e Branca, editado por Francesco Galgano. Bologna: Zanichelli Editore.

CORBERÁ MARTÍNEZ, José M.. 2005. «El principio de educación, formación e información como pilar básico del concepto de cooperativa». CIRIEC-ESpaña, Revista jurídica de economia social y cooperativa, 16: 101-130.

COSTA, Ferreira da. 1983. António Sérgio e a Democracia Cooperativa. Lisboa: INSCOOP.

COSTA, Ricardo. 2018. "Artigo 29. ${ }^{\circ}$ ». In Código Cooperativo Anotado, editado por Deolinda Meira e Maria Elisabete Ramos, 174-181. Coimbra: Almedina.

CUNHA. CAROLINA. 2018. "ARTIGO 112. "». IN CÓDIGO COOPERATIVO ANOTADO, editado por Deolinda Meira e Maria Elisabete Ramos, 590-598. Coimbra: Almedina.

FAJARDO GARCÍA, Isabel-Gemma. 1997. La gestión económica de la cooperativa, Madrid: Tecnos.

FAJARDO GARCÍA, Isabel-Gemma. 2015. "Orientaciones y aplicaciones del principio de participación económica», CIRIEC-España, Revista Jurídica de Economía Social y Cooperativa, Monográfico, 27: 205-241.

FAJARDO, Gemma., FICl, Antonio., HENRŸ, Hagen, HIEZ, David, MEIRA, Deolinda, MÜNKNER, Hans-H. \& SNAITH, Ian. 2017. Principles of European Cooperative Law. Principles, Commentaries and National Reports. Cambridge: Intersentia. DOI: https://doi.org/10.1017/9781780686073

FAJARDO, Gemma. \& MEIRA, Deolinda. 2017. «Cooperative Financial Structure«. In Principles of European Cooperative Law. Principles, Commentaries and National Reports, editado por Gemma Fajardo, Antonio Fici, Hagen Henrÿ, David Hiez, Deolinda Meira, Hans.-H. Münkner \& Ian Snaith, 73-96. Cambridge: Intersentia. DOI: https://doi. org/10.1017/9781780686073.005

$\mathrm{FICl}$, Antonio. 2013. "Cooperative Identity and the Law». European Business Law Review, 24: 37-64.

$\mathrm{FICl}$, Antonio. 2015. "La función social de las cooperativas: notas de derecho comparado». REVESCO, Revista de Estudios Cooperativos, 117: 77-98. Doi: https://doi.org/10.5209/rev_REVE.2015.v117.48146

$\mathrm{FICl}$, Antonio. (2018a. "Artigo 21. `». In Código Cooperativo Anotado, editado por Deolinda Meira e Maria Elisabete Ramos, 129-134. Coimbra: Almedina.

$\mathrm{FICl}$, Antonio. 2018b. «Artigo 22. ${ }^{\circ}$ ». In Código Cooperativo Anotado, editado por Deolinda Meira e Maria Elisabete Ramos, 135-138. Coimbra: Almedina.

GARCÍA PEDRAZA, Lienny, GARCÍA RUIZ, Jaime Gabriel \& FIGUERAS MATOS, Dagoberto. 2018. «Importancia de la educación cooperativa. Una experiencia cubana». REVESCO, Revista de Estudios Cooperativos, 29: 142160. DOI: http://dx.doi.org/10.5209/REVE.6288 
GUTIÉRREZ FERNÁNDEZ, Carlos García. 1995. "Las Sociedades Cooperativas de derecho y las de hecho con arreglo a los valores y a los principios del Congreso de la Alianza Cooperativa Internacional de Manchester de1995: especial referencia a las sociedades de responsabilidad limitada reguladas en España», REVESCO, Revista de Estudios Cooperativos, 61: 53-87.

LLOBREGAT HURTADO, María Luisa. 1990. Mutualidad y empresas cooperativas. Barcelona: Bosch.

MACÍAS RUANO, Antonio José. 2015. «El Quinto Principio Internacional Cooperativo: Educación, Formación e Información. Proyección legislativa en España». CIRIEC-España, Revista jurídica de economia social y cooperativa, 27: 243-284.

MACPHERSON, Ian. 1996. Princípios Cooperativos para o Século XXI, Colecção «Estudos». Lisboa: INSCOOP.

MARTÍNEZ CHARTERINA, Alejandro. 2015. "Las cooperativas y su acción sobre la sociedad». REVESCO, Revista de Estudios Cooperativos, 117: 34-49. Doi: http://dx.doi.org/10.5209/rev_REVE.2015.v117.48144

MARTINS, Alexandre Soveral. 2018. "Artigo 28. ${ }^{\circ}$. In Código Cooperativo Anotado, editado por Deolinda Meira e Maria Elisabete Ramos, 167-163. Coimbra: Almedina.

MEIRA, Deolinda. 2009. O regime económico das cooperativas no direito português: o capital social. Porto: Vida Económica.

MEIRA, Deolinda. 2011a. «O quadro jurídico-constitucional do cooperativismo em Portugal». Cooperativismo e Economia Social, 33: 31-46.

MEIRA, Deolinda. 2011b. «A reserva legal nas cooperativas». Revista de Ciências Empresariais e Jurídicas, 19: 7-25.

MEIRA, Deolinda. 2012. "Cooperative social responsibility: An Intercultural Analysis». In Permanent Transit. Discourses and Maps of the Intercultural Experience, editado por Clara Sarmento, 127-144. Cambridge Scholars Publishing.

MEIRA, Deolinda \& RAMOS, Maria Elisabete. 2014. Governação e regime económico das cooperativas. Estado da arte e linhas de reforma. Porto: Vida Económica.

MEIRA, Deolinda Meira \& Maria Elisabete RAMOS, 2015. «Os princípios cooperativos no contexto da reforma do Código Cooperativo português». CIRIECEspaña, Revista jurídica de economía social y cooperativa, 27: 401-428.

MEIRA, Deolinda. 2016a. "A fiscalização das cooperativas à luz do novo Código Cooperativo português». CIRIEC-España, Revista jurídica de economia social y cooperativa, 28: 281-327.

MEIRA, Deolinda. 2016b. "O regime económico das cooperativas à luz do novo Código Cooperativo português». Boletín de la Asociación Internacional de Derecho cooperativo, 50: 334-336. DOI: http://dx.doi. org/10.18543/baidc-50-2016pp309-347.

MEIRA, Deolinda. 2017. «Reflexões em torno do regime jurídico da reserva de educação e formação cooperativas». In O Pensamento Feminino na Construção do Direito Cooperativo, editado por M. Ferraz Teixeira \& M. Ferraz Teixeira, 57-72. Brasília: Vincere Editora. 
MEIRA, Deolinda. 2018a. «O princípio da participação económica dos membros à luz dos novos perfis do escopo mutualístico». Boletín de la Asociación Internacional de Derecho Cooperativo, 53: 107-137. DOI: http:// dx.doi.org/10.18543/baidc-53-2018pp107-137

MEIRA, Deolinda. \& RAMOS, Maria Elisabete. 2018. "Artigo 40. `». In Código Cooperativo Anotado, editado por Deolinda Meira e Maria Elisabete Ramos, 230-234). Coimbra: Almedina.

MEIRA, Deolinda, BANDEIRA, Ana Maria \& ÁVIDA, Patrícia. 2018. «Literacy in the cooperative sector evaluated through the reserve for cooperative education and training». CIRIEC-España, Revista de economía publica, social y cooperativa, 94: 61-89. DOI: https://doi.org/10.7203/CIRIEC-E.94.12733

MEIRA, Deolinda. 2019. "Identidade cooperativa, admissão e demissão dos cooperadores. Realidades convergentes no direito português». In Direito Cooperativo e Identidade Cooperativa, editado por J. Miranda, L. Sousa \& E. Gadea, 71-96. Curitiba: Brazil Publishing.

MEIRA, Deolinda \&, RAMOS, Maria Elisabete. 2019. «Projeções do princípio da autonomia e da independência na legislação cooperativa portuguesa». Boletín de la Asociación Internacional de Derecho Cooperativo, 55: 135-170.

MOZAS MORAL, Adoración. 2001. «Los órganos de gobierno y administración de la Sociedad Cooperativa: las entradas y las salidas de socios» In La Sociedad Cooperativa: un análisis de sus características societárias y empresariales, editado por José Moyano Fuentes. Jáén: Universidad de Jaén.

MOZAS, A.; MOYANO, J.; SENISE, O.; PARRAS, M. \& MURGADO, E.M. 2005. «Cultura cooperativa y eficiencia empresarial: Una contrastación en el cooperativismo oleícola». REVESCO, Revista de Estudios Cooperativos, 85: 4160.

MONZÓN, José Luis. 1995. "As cooperativas de trabajo asociado ante la reforma de los principios cooperativos». REVESCO, Revista de Estudios Cooperativos, 61: 47-52.

MÜNKNER, Hans-H.. 1982. Nueve Lecciones de Derecho Cooperativo. Marburgo:Friedrich-Ebert-Stiftung.

MÜNKNER, Hans-H.. 1995. Chances of Co-operatives in the Future. Contribution to the International Co-Alliance Centennial 1895-1995. Marburgo:Lahn.

NAMORADO, Rui.1995. Os Princípios Cooperativos. Coimbra: Fora do Texto.

NAMORADO, Rui. 1999. As cooperativas, empresas que são associações. Coimbra: Faculdade de Economia da Universidade de Coimbra.

NAMORADO, Rui. 2001. "A Identidade Cooperativa na Ordem Jurídica Portuguesa», Oficina do Centro de Estudos Sociais, 157. Coimbra: Faculdade de Economia da Universidade de Coimbra.

NAMORADO, Rui. 2005. Cooperatividade e Direito Cooperativo. Estudos e pareceres. Coimbra: Almedina.

NAMORADO, Rui. 2018. "Artigo 3. ${ }^{\circ}$ ", In Código Cooperativo Anotado, editado por Deolinda Meira e Maria Elisabete Ramos, 28-36. Coimbra: Almedina.

PITA, Manuel António. 1989. Direito aos lucros. Coimbra: Almedina. 
RACUGNO, Grabiele. 2006. "La Società Cooperativa».In Trattato di Diritto Commerciale, Sezione IV, Tomo 9, editado por Vincenzo Buonocore, Toirno: G. Giappichelli Editore.

RODRÍGUEZ GONZÁLEZ, Amalia. 2018. «Educación, Formación e Información de los socios en las cooperativas (un principio cooperativo al servicio del fomento del empleo de calidad)». CIRIEC-España, Revista jurídica de economía social y cooperativa, 33:105-144.

ROMERO CIVERA, A.. 2010. «El fondo de educación y promoción en cooperativas de crédito: su gestión con o sin una función». REVESCO, Revista de Estudios Cooperativos, 101: 58-78.

SÉRGIO, António. 1974. Sobre o socialismo de Oliveira Martins, Ensaios, tomo VIII. Lisboa: Sá da Costa Editora.

SNAITH, Ian. 2017. "Chapter 2. Cooperative Governance». In Principles of European Cooperative Law. Principles, Commentaries and National Reports, editado por Gemma Fajardo, Antonio Fici, Hagen Henrÿ, David Hiez, Deolinda Meira, Hans.-H. Münkner \& Ian Snaith, 47-72. Cambridge: Intersentia. DOI: https://doi.org/10.1017/9781780686073.005

TORRES LARA, Carlos. 1983. Cooperativismo- el modelo alternativo. Lima: Universidad de Lima.

VARGAS SÁNCHEZ, Alfonso. 1999. «De la participación en la empresa a la empresa de participación democrática». REVESCO, Revista de Estudios Cooperativos, 67: 219-234. 


\section{Derechos de autor}

El Boletín de la Asociación Internacional de Derecho Cooperativo es una revista de acceso abierto lo que significa que es de libre acceso en su integridad inmediatamente después de la publicación de cada número. Se permite su lectura, la búsqueda, descarga, distribución y reutilización legal en cualquier tipo de soporte sólo para fines no comerciales y según lo previsto por la ley; sin la previa autorización de la Editorial (Universidad de Deusto) o el autor, siempre que la obra original sea debidamente citada (número, año, páginas y DOI si procede) y cualquier cambio en el original esté claramente indicado.

\section{Copyright}

The International Association of Cooperative Law Journal is an Open Access journal which means that it is free for full and immediate access, reading, search, download, distribution, and lawful reuse in any medium only for non-commercial purposes, without prior permission from the Publisher or the author; provided the original work is properly cited and any changes to the original are clearly indicated. 